\title{
Correction to: A Translational Quantitative Systems Pharmacology Model for CD3 Bispecific Molecules: Application to Quantify T Cell-Mediated Tumor Cell Killing by P-Cadherin LP DART®
}

\author{
Alison Betts, ${ }^{1,2,10}$ Nahor Haddish-Berhane, ${ }^{3}$ Dhaval K. Shah, ${ }^{4}$ Piet H. van der Graaf, ${ }^{2}$ Frank Barletta, ${ }^{5}$ \\ Lindsay King, ${ }^{6}$ Tracey Clark, ${ }^{7}$ Cris Kamperschroer, ${ }^{8}$ Adam Root, ${ }^{1}$ Andrea Hooper, ${ }^{5}$ and Xiaoying Chen'
}

Published online 4 June 2019

\section{Correction to: AAPS J \\ https://doi.org/10.1208/s12248-019-0332-Z}

Typesetting error occurred and Figure 1a and Figure 1b were altered during the uploading process. The original article has been corrected.

Publisher's Note Springer Nature remains neutral with regard to jurisdictional claims in published maps and institutional affiliations.

The online version of the original article can be found at https:// doi.org/10.1208/s12248-019-0332-z

${ }^{1}$ Department of Biomedicine Design, Pfizer Inc., 610 Main Street, Cambridge, Massachusetts 02139, USA.

${ }^{2}$ Division of Systems Biomedicine and Pharmacology, Leiden Academic Centre for Drug Research, 2300 RA, Leiden, The Netherlands.

${ }^{3}$ Janssen Research \& Development, LLC, Spring House, Pennsylvania 19477, USA.

${ }^{4}$ Department of Pharmaceutical Sciences, 455 Kapoor Hall, University at Buffalo, The State University of New York, Buffalo, New York 14214-8033, USA.

${ }^{5}$ Oncology Research Unit, Pfizer Inc., 401 N Middletown Rd., Pearl River, New York 10965, USA.

${ }^{6}$ Department of Biomedicine Design, Pfizer Inc., 1 Burtt Road, Andover, Massachusetts, USA.

${ }^{7}$ Established Med Business, Pfizer Inc., Eastern Point Rd, Groton, Connecticut 06340, USA.

${ }^{8}$ Department of Immunotoxicology, Pfizer Inc., 558 Eastern Point Road, Groton, Connecticut 06340, USA.

${ }^{9}$ Department of Clinical Pharmacology, Pfizer Inc., 10555 Science Center Dr., San Diego, California 92121, USA.

${ }^{10}$ To whom correspondence should be addressed. (e-mail: alison.betts@pfizer.com) 